\title{
MEIOS DE COMUNICAÇÃO E A LETALIDADE INFANTOJUVENIL: um estudo empírico sobre a política de proteção no Brasil
}

\author{
Rômulo Magalhães Fernandes \\ Anna Carolina de Oliveira Azevedo 2
}

\section{Palavras-Chave}

adolescentes / crianças / meios de comunicação / PPCAAM / proteção

\section{SUMÁRIO}

\section{Introdução. 20 espetáculo da notícia e banalização da violência nos meios de comunicação 3. A violência letal contra crianças, adolescentes e jovens e os meios de comunicação. 4. A proteção de crianças, adolescentes e jovens ameaçados de morte. 5. A relação entre - PPCAAM e os meios de comunicação. 6. Conclusões. 7. Referências.}

\section{Resumo}

$\mathrm{Na}$ atualidade, o uso das novas tecnologias de informação e comunicação e a sua relação com a segurança tornam-se cada vez mais relevantes. Essa reflexão ganha maior centralidade no contexto de políticas de proteção, como é o caso do Programa de Proteção a Crianças e Adolescentes Ameaçados de Morte (PPCAAM). A partir de um estudo teórico e empírico, o presente artigo visa refletir sobre a relação entre os meios de comunicação e a política de proteção do PPCAAM no Brasil, tendo em vista os parâmetros definidos na Constituição Federal de 1988, no Estatuto da Criança e do Adolescente e no Decreto Federal que cria e regulamenta a referida política. Num cenário de avanço tecnológico e de espetacularização da mídia, o PPCAAM precisa aperfeiçoar a sua metodologia, em particular, quanto ao uso das ferramentas virtuais com as quais os usuários e os profissionais deste Programa estão cotidianamente em contato, assim como denunciar eventuais situações de abuso quando os protegidos são expostos indevidamente pelos meios de comunicação. Ressalta-se, ainda, a necessidade da construção de uma cultura de segurança e de respeito aos direitos humanos no contexto de trabalho do PPCAAM, de forma a estabelecer senso crítico sobre a relação entre proteção e meios de comunicação. 


\section{MEDIA AND INFANT-YOUTH LETHALITY: an empirical study on protection policy in Brazil}

Rômulo Magalhães Fernandes 3

Anna Carolina de Oliveira Azevedo 4

\section{Keywords}

adolescents / children / media /

PPCAAM / protection.

\section{SUMMARY}

1. Introduction. 2 The spectacle of news and the trivialization of violence in the media 3. Lethal violence against children, adolescents and young people and the media. 4. The protection of children, adolescents and young people threatened with death. 5. The relationship between PPCAAM and the media. 6. Conclusions. 7. References.

\section{Abstract}

At present, the use of new information and communication technologies and their relationship with security are becoming increasingly relevant. This reflection gains greater centrality in the context of protection policies, as is the case of the Program for the Protection of Children and Adolescents Threatened with Death (PPCAAM). In this sense, from a theoretical and empirical study, this article aims to reflect on the relationship between the media and the protection policy of PPCAAM in Brazil, considering the parameters defined in Federal Constitution de 1988, ECA and the Federal Decree that creates and regulates such a policy. With the technological advancement and the spectacularization of the media, the PPCAAM needs to improve its methodology, in particular, regarding the use of virtual tools with which the users and professionals of this Program are in daily contact, as well as to denounce eventual situations of abuse when their protégés are unduly exposed by the media. Finally, the need to build a culture of security and respect for human rights in the context of the PPCAAM work is emphasized, in order to establish a critical sense of the relationship between protection and the media. 


\section{INTRODUÇÃO}

O assassinato de crianças e adolescentes é uma grave forma de violência que possui diferentes dimensões e, dessa forma, necessita de ações articuladas para a formulação e implementação de políticas públicas que sejam eficazes no seu enfrentamento. Dentre essas políticas, destaca-se o Programa de Proteção a Crianças e Adolescentes Ameaçados de Morte (PPCAAM), criado em 2003.

O PPCAAM é uma das estratégias do Estado brasileiro para a reversão do quadro de violência letal contra crianças e adolescentes no país. Trata-se de um Programa de Proteção composto por profissionais de diversos campos de atuação (Direito, Serviço Social, Psicologia e Educação), com a função de elaborar um plano de segurança e gerir os procedimentos de proteção de pessoas em situação de risco extremo.

A metodologia do PPCAAM, sintetizada em seu Guia de Procedimentos, aborda o tema da comunicação de maneira breve, com destaque para duas passagens: a primeira, que associa os meios de comunicação à análise de gravidade da ameaça; e a segunda, que fala sobre os compromissos firmados com os protegidos e seus familiares durante o processo de inclusão no Programa, que incluem o cuidado com o sigilo e a não exposição mediante os meios de comunicação (Soares \& Egas, 2010, pp. 66-89).

Nesse sentido, o presente artigo tem como objetivo refletir sobre a relação entre os meios de comunicação e a política de proteção do PPCAAM, tendo em vista os parâmetros definidos na Constituição da República de 1988 (CF/88), no Estatuto da Criança e do Adolescente (ECA) e no Decreto Federal $n^{\circ}$. 6.231, de 11 de outubro de 2007, que cria e regulamenta tal política. Para tanto, optou-se por um estudo qualitativo e de caráter exploratório, estruturado sob a forma de análise bibliográfica e empírica.

Entende-se que essa abordagem oportuniza a formulação de descrições aprofundadas de contextos, processos e mecanismos pouco conhecidos ou pouco explorados, possibilitando, assim, um melhor entendimento sobre a atuação estatal e a produção de conhecimento aplicável ao seu aprimoramento. Considera-se que tal entendimento é um desafio relevante quando se trata de políticas públicas contra situações de violência e violação de direitos de pessoas em condição peculiar de desenvolvimento humano.

Assim, em um primeiro plano, realiza-se uma revisão bibliográfica interdisciplinar, com destaque para contribuições de Guy Debord, Loïc Wacquant e outros autores, tendo por foco as noções de "sociedade do espetáculo" e de "adesão subjetiva à barbárie", que conformam o contexto analítico mais amplo do texto e dos campos de estudo conexos, como o Direito e a Comunicação Social. Além disso, o estudo teórico também considera a análise da legislação constitucional e infraconstitucional diretamente vinculada ao tema da criança e do adolescente.

Em um segundo plano, depois de fixado o referencial teórico da pesquisa, desenvolve-se um estudo empírico, de forma a auxiliar a análise qualitativa do cenário que compõe o universo da mídia sobre crianças, adolescentes e jovens incluídos no Programa de Proteção. Mais do que traçar dados quantificáveis, o método adotado visa levantar uma gama de informações que permitam estudar o PPCAAM com sua devida complexidade, considerando as múltiplas características e relações nas quais as pessoas 
atendidas por essa política estão inseridas (Igreja, 2017).

Desse modo, a base de dados do estudo compreende a sistematização e a análise de questionários respondidos por 10 (dez) equipes técnicas do PPCAAM, de diferentes estados do Brasil, obtidos em parceria com - Grupo de Trabalho Nacional sobre Mídia e PPCAAM e a partir de pesquisa desenvolvida no Programa de Pós-graduação em Direito Público da PUC Minas nos anos de 2015 e 2016.

Além desses dois planos de estudo, bibliográfico e empírico, vale citar, ainda, a vinculação funcional de um dos autores, que, por cinco anos, trabalhou como coordenador nacional do Grupo de Trabalho Mídia e PPCAAM, experiência que incluiu a atuação frente a problemas ligados à exposição indevida desses protegidos pela mídia. Isso também justifica a opção pelo desenvolvimento da pesquisa ao ponto de evidenciar limites e possibilidades na relação entre políticas públicas de crianças e adolescentes e os meios de comunicação social, contribuindo para a maior oferta de análises com foco nas experiências de proteção desse público, ou, em sentido mais abrangente, da prática dos direitos humanos como uma realidade cotidiana.

Nesse cenário de investigação, as seguintes perguntas guiaram o desenvolvimento do estudo em questão: como se caracterizam os meios de comunicação na atualidade? A banalização da violência na mídia favorece uma exposição indevida do público infantojuvenil? Como se dá a relação entre os usuários e profissionais da política de proteção do PPCAAM e os meios de comunicação em geral? Ou, ainda, como se pode qualificar o uso das tecnologias da informa- ção pelos usuários e profissionais da equipe técnica do PPCAAM?

A busca por respostas a tais indagações motiva o presente artigo a refletir sobre o PPCAAM e os meios de comunicação, em particular, sobre o papel das novas Tecnologias da Informação e Comunicação (TICS) na sociedade atual, marcada pela interação em rede e pela banalização da violência como artifício da espetacularização da notícia. Almeja-se, nesse sentido, contribuir com futuros apontamentos que assegurem o direito à comunicação e a não exposição daqueles que estão inseridos no contexto de proteção.

De forma resumida, além desta introdução, o artigo é organizado em quatro eixos centrais de discussão. Inicialmente, aborda-se o contexto midiático caracterizado pela notícia do espetáculo e a banalização da violência na atualidade. A seguir, propõe-se a análise do tema da violência letal contra crianças, adolescentes e jovens em uma sociedade cada vez mais midiatizada e organizada em rede. Em sequência, estuda-se o PPCAAM, apresentando um quadro geral dos usuários, profissionais e metodologia dessa política de proteção. Por último, apresenta-se a relação entre o PPCAAM e os meios de comunicação a partir da análise de dados empíricos, destacando os efeitos da exposição indevida dos protegidos pelos meios de comunicação.

\section{ESPETÁCULO DA NOTÍ́CIA E BANALIZAÇÃO DA VIOLÊNCIA NOS MEIOS DE COMUNICAÇÃO}

Hoje, as mudanças do modo de produção e de consumo dos meios de comunicação de massa alteraram os processos comunicativos de informar e informar-se e, nesse ponto, as narrativas que veiculam a notícia também se modificaram. As fronteiras que 
delimitavam a noção de tempo e espaço, por exemplo, alteraram o significado do que antes se chamava de "furo", "exclusividade" e "fatos de última hora".

Essas categorias ainda existem, mas incidem sobre a realidade e a vida cotidiana das pessoas com outra velocidade. Além disso, os programas de TV, articulados com as plataformas digitais, assumem como tarefa principal prender a atenção de sua audiência, mesmo que, para isso, seja preciso aplicar técnicas não convencionais que reforçam o culto à imagem e a relativização da privacidade das pessoas.

Se a mensagem informativa precisa ser continuamente nova e cativar seus receptores, torna-se necessário retirar dela tudo aquilo que exige maior reflexão e comparação entre diferentes fontes. $O$ contrário poderia afetar a audiência e, consequentemente, os anunciantes desse veículo de comunicação social. Precisa-se de algo que agrade o gosto do grande público, isto é, que contemple uma narrativa de fatos de forte impacto emotivo e que possa gerar efeitos a qualquer pessoa, pelo menos, em expectativa.

Vive-se, assim, o tempo da urgência, em que o espetáculo da notícia deixa em segundo plano a objetividade dos fatos, para dar visibilidade ao alarde social.

A urgência da notícia de "último momento", predominando sobre a informação e construída na maioria das vezes com casos fatais, simplifica os critérios de noticiabilidade, que agora residem na espetacularidade armada pelos efeitos da câmera, na gravidade e na proximidade dos eventos. Como a urgência está associada ao alarme e, até mesmo, à ameaça da vida cotidiana, são notícias que afir- mam a dificuldade do exercício do governo e a necessidade de maior controle da sociedade. É uma informação indubitavelmente de sentido político: o mundo é o palco espetacular, e a geografia conflitiva, terrível, amedrontada por ser instantânea e aparente (Martini, 2008, p. 219).

No espetáculo alarmante da notícia, o "furo" e a "urgência" assumem a narrativa dos fatos pela brevidade e pela banalidade da violência. Pouco importa se existem informações fundamentadas que comprovem a alta probabilidade das pessoas sofrerem algum tipo de violência ao saírem de casa; o que interessa, de fato, é a sensação de insegurança que se projeta na subjetividade das pessoas.

Nesse ponto, Vera Malaguti Batista (2012, p. 316) lembra que: "não por acaso é o medo, e não o risco, o grande avalizador das políticas públicas dirigidas ou não à questão criminal". Pensamento similar também se percebe em Bauman (2008), quando ele afirma que hoje existe uma sensação de medo que gera insegurança, insinuando, mesmo que institivamente, que há um permanente perigo que ameaça e pode atacar a qualquer momento, sem aviso prévio.

Em uma sociedade pautada pelo medo e pelo sentimento de insegurança, a agenda dos meios de comunicação acolhe, cada vez mais, temas de grande comoção: violência, tragédia, miséria, dor, insegurança, corrupção, vingança e injustiça, tendo como foco principal a política pública de segurança e seus atores sociais. Um deles é o governo, geralmente, abordado de forma distante e genérica, recebedor de queixas de todo tipo, às vezes, até de maneira paradoxal.

Cita-se, por exemplo, a política pública de 
atendimento ao adolescente infrator, que, ao mesmo tempo em que é objeto de queixas pela falta de vagas nas casas de internação, é questionada quanto à priorização de recursos públicos na sua manutenção, isso sem qualquer contextualização ou conexão prévia entre as ideias.

Recorrentemente, a pauta da narrativa midiática envolve aqueles atores que representam algum tipo de ameaça à "normalidade" social, ou seja, indesejáveis de toda ordem (infratores, suspeitos, moradores de rua, bandidos, pedintes, pivetes, etc.), que, não raramente, também são associados às "soluções" dos problemas, tais como: o endurecimento das penas, a institucionalização do público infantojuvenil e a criminalização dos considerados diferentes.

Mas, de onde vem a força do espetáculo? Ou, em outra perspectiva, como essas representações midiáticas de "soluções" simplificadoras tornam-se padrões, que são aceitos e reproduzidos pela grande audiência desses meios de comunicação? Nesse ponto, os meios de comunicação devem ser entendidos dentro de um contexto maior, no qual a interação entre os veículos de comunicação e a sociedade estabelecem relações assimétricas de poder, favorecendo a prevalência desta ou daquela visão de mundo.

Entretanto, no caso da mídia, apenas isso não explica por completo tal fenômeno. Para que determinados consensos sejam estabelecidos de forma hegemônica, também caberá aos meios de comunicação interagir com as experiências, convicções e expectativas do conjunto de pessoas que se pretende influenciar. Prevalece, assim, uma das teses indicadas por Guy Debord (2000, p. 14), no sentido que "o espetáculo não é um conjunto de imagens, mas uma relação social entre pessoas, mediada por imagens".

O conceito de "sociedade do espetáculo", idealizado pelo autor francês na década de 1960, considera que, ao se analisar a sociedade capitalista, está presente um acúmulo de imagens, que estabelecem o predomínio da imagem sobre a coisa, da cópia sobre o original, da representação sobre a realidade, da aparência sobre o ser. Conforme Debord, o ponto inicial é o modo de produção, sendo seguido pelo consumo do espetáculo, no qual as pessoas não vivem mais suas próprias experiências, mas os modelos dos quais a experiência se faz representada. Nas palavras do autor: "tudo o que era vivido se esvai na fumaça da representação" (Debord, 2000, p. 13).

Para Debord (2000), o espetáculo não é um conjunto de imagens, mas uma relação social entre pessoas, mediatizada por imagens, no qual a TV torna-se o canal privilegiado do espetáculo, ao definir regras, conceitos, comportamentos e, principalmente, pelo poder de evidenciar ou silenciar determinados fatos. Inspirado na ideia de fetichismo da mercadoria de Karl Marx, segundo a qual as relações entre os homens passaram a ser mediadas pelas coisas, Debord (2000) inclui o papel das imagens nessa relação. Se, em uma primeira fase, do domínio da economia sobre a vida, as relações sociais caracterizavam-se pela degradação do "ser" em "ter", no domínio do espetáculo chega-se ao reinado soberano da "aparência" (Patias, 2012, pp. 93-94).

Quando se analisa a relação entre os meios de comunicação e a representação do público infantojuvenil, especialmente aquele que se aproxima do perfil atendido pelo PP- 
CAAM (assunto analisado adiante), o uso do espetáculo sem qualquer compromisso ético ou social ganha força a partir da passagem do espetáculo ao simulacro, em que a encenação do acontecimento pode levar à manipulação dos fatos como mera representação do real e definir os sentidos que ditam a política. Esse cenário é um ambiente propício para que seja estimulado o senso comum e o que este anseia com maior voracidade: a punição e a contenção dos indesejáveis em reposta ao medo e à sensação de insegurança.

Vera Malaguti Batista (2012, pp. 308-310), ao analisar os textos de Wacquant, chama atenção para o fenômeno atual de adesão subjetiva à barbárie, como parte integrante da expansão e da reorganização da prisão e de seus tentáculos institucionais. Segundo a autora, trata-se de uma reforma da paisagem sociossimbólica, reconstruindo e reconfigurando o próprio Estado que se converteu em Estado penal como "potente motor cultural", com seus próprios direitos, categorias, classificações e imagens.

A adesão subjetiva à barbárie, por sua vez, passa a constituir-se conjuntamente com a crescente demanda coletiva por castigo e punição, tendo essa pulsante cultura punitiva a figura da vítima como seu principal dispositivo e o medo como sua potente metodologia. Desse medo, portanto, é que se funda e se desenvolve o capital simbólico capaz de reproduzir subjetividades e assujeitamentos às pessoas.

A partir do quadro teórico apresentado acima, que busca caracterizar a narrativa midiática presente nos meios de comunicação social contemporâneos, busca-se, na sequência, analisar o contexto específico de crianças, adolescentes e jovens em situação de ameaça de morte e/ou vítimas da violência letal.

\section{A VIOLÊNCIA LETAL CONTRA CRIANÇAS, ADOLESCENTES E JOVENS E OS MEIOS DE COMUNICAÇÃO}

Para muitas entidades de promoção de direitos humanos de crianças e adolescentes, a exemplo do United Nations Children's Fund (UNICEF, 2015), o Estatuto da Criança e do Adolescente (ECA) representou uma das principais experiências legislativas da América Latina, uma vez que conseguiu, como poucas leis infraconstitucionais, traduzir em âmbito nacional os princípios que norteiam a Convenção sobre Direitos da Criança, de 1989, e outros tratados internacionais de direitos humanos dela correlatos.

Contraditoriamente, nos últimos anos, a realidade brasileira caminha à margem do que a lei se propõe quanto ao predomínio da proteção do público infantojuvenil contra a violência letal que possam estar submetidos. Nesse ponto, a publicação comemorativa dos 25 anos do ECA, lançada em 2015 pelo UNICEF, aborda o contraste que a entidade considera o mais grave: hoje, as chances de uma criança ou um adolescente morrer assassinado no Brasil mostram-se maiores do que em 1990, ano de promulgação do ECA; a indicar que algo não caminha bem.

Mas qual a extensão do problema da letalidade infantojuvenil? Na tentativa de responder tal questão, três pesquisas quantitativas e qualitativas podem ser citadas: o Atlas da Violência (IPEA \& FBSP, 2018), o Índice de Homicídio na Adolescência (Cano \& Borges, 2017) e o Mapa da Violência (Waiselfisz, 2015). Tais pesquisas revelam que o Brasil é um dos países mais violentos do mundo e que tem entre os mais jovens, na maioria homens, negros e moradores de regiões periféricas das cidades, as principais 
vítimas dessa triste realidade. Trata-se, assim, do problema da banalização da violência, em que o extermínio físico das pessoas em desenvolvimento torna-se cotidiano e parte integrante de uma agenda política de segunda ordem pelo Estado, pela sociedade e pela grande mídia.

Conforme o Atlas da Violência, no ano de 2016, último ano de dados disponíveis da pesquisa, o Brasil atingiu número recorde de homicídios, alcançando um total de 62.517 mortes letais, o que representa a taxa de 30,3 homicídios para cada 100 mil pessoas. A título de comparação, o número total de homicídios foi $5 \%$ maior do que no ano anterior e 14\% maior do que o registrado dez anos antes. Ao longo da década de 2006 a 2016, o aumento do número de mortes foi praticamente contínuo, saindo do patamar de 49,7 mil mortes até chegar aos números mais recentes.

Nota-se, também, que esse cenário não se reproduz da mesma forma em todos os segmentos da população, pois existem aqueles, como é o caso dos mais jovens, que a proporção de assassinados é ainda mais expressiva. Das 62 mil vítimas de homicídio, 33,6 mil tinham entre 15 e 29 anos, alcançando uma taxa de homicídio, entre os jovens, de 65,5 por 100 mil pessoas. Em outros termos, entre os jovens, o risco de morrer assassinado é mais do que o dobro da média da população. E, se considerados os homens jovens, a situação é ainda mais grave, na medida em que são 123 homicídios a cada grupo de 100 mil pessoas, isto é, quatro vezes a média do país.

Em uma abordagem diferente daquela do Atlas da Violência, o Índice de Homicídios na Adolescência (IHA), desenvolvido pelo Programa de Redução da Violência Letal, busca estimar o risco de mortalidade por homicídio de adolescentes que residem em um determinado território, visando exemplificar o impacto da violência letal neste grupo social e monitorar o fenômeno como forma de subsidiar as políticas públicas de prevenção na área. Na prática, o valor do IHA representa o número de adolescentes mortos por homicídio entre 12 e 18 anos para cada grupo de mil pessoas.

Segundo o IHA, estima-se que, se nada for feito para alterar as condições do ano de 2014, 43 mil adolescentes poderão ser mortos, entre 2015 e 2021, nos 300 municípios brasileiros com mais de 100 mil habitantes, representando o número mais alto já registrado pela pesquisa, elaborada desde 2005. Em termos gerais, nesses municípios analisados, a taxa de assassinatos de jovens chegou a 3,65 por mil adolescentes, ou seja, para cada mil adolescentes que completam 12 anos, mais de três são vítimas de homicídios antes de chegar aos 19 anos. No Nordeste, região com números mais alarmantes, o índice é de 6,5 por mil adolescentes, o que representa um aumento maior que o dobro se comparado com a pesquisa do ano de 2005.

O IHA aborda, ademais, parâmetros de gênero, cor, idade e meio utilizado no homicídio, reforçando a tendência apresentada no Atlas da Violência, uma vez que, em 2014, ano da pesquisa do IHA, notou-se que os adolescentes do sexo masculino têm um risco 13,52 vezes superior ao das adolescentes do sexo feminino. Notou-se, também, que os adolescentes negros apresentam um risco 2,88 vezes superior ao dos brancos e que as chances de ser morto por arma de fogo é 6,11 vezes maior do que por outros meios.

Do IHA observa-se, ainda, que a violência letal não atinge somente os adolescentes, pois os grupos de jovens com idade entre 19 
e 24 anos têm risco de morrer por homicídio quase duas vezes superior ao grupo de adolescentes.

Essas duas pesquisas ajudam a elucidar que existe um perfil da violência no país, que incide com mais força em determinados territórios e grupos de pessoas, além de privilegiar o uso de meios específicos, como é o caso da arma de fogo nos atos de homicídios. Dentre os grupos sociais "contra quem" a violência é tolerada, destaca-se a juventude oriunda das classes populares, especialmente, jovens negros do sexo masculino, moradores das periferias de áreas metropolitanas das grandes cidades do país.

Outros estudos podem agregar novos elementos à análise anterior, considerando que essa violência social não deve ser tratada como um fato que seja explicado e compreendido pela ação isolada dos indivíduos, seus temperamentos, irascibilidade ou ainda pelo uso de substâncias estimuladoras, como o álcool ou as demais drogas, mas sim pelo entendimento de um contexto de violência que articula, por exemplo, o racismo e a impunidade como componentes integrantes da degradação do ambiente social brasileiro.

A violência torna-se uma linguagem cujo uso é validado pela sociedade, quando esta se omite na adoção de normas e políticas sabidamente capazes de oferecer alternativas de mediação para os conflitos que tencionam a vida cotidiana, aprofundam as desigualdades e promovem injustiças visíveis. A tradição de impunidade, a lentidão dos processos judiciais e o despreparo do aparato de investigação policial são fatores que se somam para sinalizar à sociedade que a violência é tolerável em determinadas condições, de acordo com quem a pratica, contra quem, de que forma e em que lugar ( $\mathrm{Wa}$ iselfisz, 2015, p. 9).

A vida em sociedade apresenta uma violência com muitas faces e que age de formas diferentes. A definição de violência do dicionário, por exemplo, como substantivo feminino: "qualidade ou característica de violento; ato de crueldade; emprego de meios violentos; fúria repentina; ou, por fim, a coação que leva uma pessoa à sujeição de alguém" (Michaelis, 2018), por si só, não é capaz de apresentar todas as dimensões desse fenômeno, muito menos, articulá-las em torno de um único marco conceitual.

No caso específico deste estudo, que aborda a forma de violência física que compreende os assassinatos das pessoas mais jovens, não se pretende ignorar a relação dessa última com as demais dimensões da violência, que são múltiplas e que podem se articular mutuamente, a exemplo das violências institucional e simbólica.

A vertente da violência institucional pode ser ilustrada, sobretudo, pelo elevado número de mortes cometidas por policiais ao longo das últimas décadas, em serviço ou fora dele. Grande parte dos casos não é sequer investigada em razão das alegações de "autos de resistência" ou "homicídio decorrente de intervenção policial". Segundo dados da Anistia Internacional (2015, p. 1), dos 220 registros de homicídios decorrentes de intervenção policial na cidade do Rio de Janeiro em 2011, apenas uma denúncia havia sido feita por parte do Ministério Público contra os policiais envolvidos e $83 \%$ das investigações ainda não tinham sido concluídas até abril de 2015.

Vê-se, assim, que a redemocratização do país e a sua configuração como Estado De- 
mocrático de Direito não foram capazes de alterar o quadro de violência estatal e de letalidade da atuação policial. Esse cenário de violência letal articula-se com o grande arsenal de armas de fogo existente no país e produz o seguinte quadro: das 39.686 vítimas de disparo de qualquer tipo de arma de fogo, em 2012, 28.946 eram negros e 10.632, brancos (Waiselfisz, 2015). O elevado número de "mortes matadas por armas de fogo" é atribuído ao arbítrio das polícias, às balas perdidas entre traficantes e aos confrontos entre os próprios jovens, em uma das poucas alternativas de trabalho e ocupação que representa o tráfico de drogas.

Na dimensão da violência simbólica, destaca-se o papel da mídia sobre a leitura desse fenômeno. A percepção seletiva da violência a presenta-se na cobertura midiática e na comoção diferenciada da opinião pública, a depender da cor da pele e da origem social do jovem vítima de violência. Conforme expresso por Silvia Ramos, "na medida em que o perfil das vítimas de homicídios fica mais negro, mais pobre e mais nordestino, a tendência é que a indiferença e a naturalização aumentem" (Ramos como citado em Trevisan, 2014, p. 1).

$\mathrm{Na}$ mesma perspectiva, a pesquisa realizada pela Agência de Notícias dos Direitos da Infância (ANDI - Comunicação e Direitos) aponta a propensão dos jornais impressos brasileiros em dissociar as violências físicas praticadas contra a população negra e o debate sobre seu contexto primordial de produção: a violência simbólica do racismo (ANDI, 2012, p. 8). Desse modo, a atividade comunicativa dos meios de comunicação social reproduz a visão hierarquizada da sociedade brasileira, com a pessoa negra situada na base da pirâmide e "invisível" na sua condição de sujeito de direitos, cidadão.

Do ponto de vista dos mais jovens, neste caso, adolescentes e jovens entre 14 e 20 anos do município do Rio de Janeiro que foram entrevistados pela pesquisa "Juventude, Violência e Cidadania" (Minayo et al., 1999), a mídia, muitas vezes, distorce as informações sobre violência, ora exagerando, ora omitindo determinados aspectos essenciais para a compreensão do evento em si. A maioria desses jovens considera que a cobertura dos meios de comunicação social mostra somente o que acontece nas favelas e periferias da cidade, reforçando a discriminação e exclusão vivenciadas pelos moradores dessas comunidades.

Isso se evidencia, por exemplo, no hiperdimensionamento da mídia sobre crimes cometidos por pessoas mais jovens e na diferenciação de enquadramento das notícias dos jornais sobre o tema do adolescente infrator: em uma perspectiva, prevalece o "menor delinquente", em outra, o "adolescente suspeito". Essa diferença explicita a existência de representações midiáticas distintas para sujeitos em contextos diversos, em um cenário no qual o número de assassinatos das pessoas mais jovens cresce e, ao mesmo tempo, ganha força na agenda política do país o discurso em defesa da redução da maioridade penal.

Como se verá adiante, tal cenário de violência, inclusive, simbólica, também se relaciona com o PPCAAM, na medida em que o surgimento dessa política está intimamente associado ao contexto do aumento significativo das taxas de homicídio no país. Situação que se torna ainda mais complexa quando essas pessoas em desenvolvimento encontram-se em um ambiente de exposição promovido pela mídia. 


\section{A PROTEÇÃO DE CRIANÇAS, ADOLESCENTES E JOVENS AMEAÇADOS DE MORTE}

Apesar do contexto de homicídios e de violações de direitos de crianças, adolescentes e jovens no Brasil, em especial, da juventude negra e pobre que reside nas periferias das grandes cidades, o tema é, em geral, tratado de forma secundária na agenda pública nacional. Dentre as escassas iniciativas dos últimos anos no enfrentamento desse cenário, vale destacar o papel desempenhado pelo Programa de Proteção a Crianças e Adolescentes Ameaçados de Morte (PPCAAM).

O PPCAAM faz parte de uma política pública pioneira, pautada na garantia dos direitos humanos das pessoas em condição peculiar de desenvolvimento. Por isso, tal Programa compreende a proteção do direito à vida a partir do fundamento da proteção integral, isto é, dos direitos humanos sob o manto do princípio do meIhor interesse da criança e do adolescente (Oliveira et al., 2011, p. 6).

O referido Programa é vinculado à Secretaria Nacional de Promoção dos Direitos da Criança e do Adolescente (SNPDCA), tendo sido criado em 2003 e reproduzido em treze Unidades da Federação ${ }^{5}$ por meio de parcerias com os governos estaduais e distrital e com organizações da sociedade civil.

Em sentido amplo, o objetivo do PPCAAM é preservar vidas de crianças, adolescentes e jovens em risco extremo,

\footnotetext{
De 2003 a 2015, a Secretaria Nacional de Promoção dos Direitos da Criança e do Adolescente (SNPDCA), representada pela Coordenação Geral de Proteção de Crianças e Adolescentes Ameaçados de Morte estabeleceu parcerias em 13 Unidades da Federação, a saber: Rio Grande do Sul, Minas Gerais, São Paulo, Paraíba, Pernambuco, Distrito Fede ral, Bahia, Paraná, Rio de Janeiro, Alagoas, Pará, Espírito Santo e Ceará Eventualmente, alguns desses estados sofreram períodos de paralisação dos serviços prestados, tendo em vista problemas conveniais.
}

além de garantir, por intermédio de medida protetiva especial, os vínculos familiares e comunitários, bem como a sua inserção social segura (Ferraz et al., 2011, p. 283). Trata-se de uma política regulamentada pelo Decreto Federal $\mathrm{n}^{\circ}$. 6.231, de 11 de outubro de 2007, que, nos termos do seu artigo $3^{\circ}$, "tem por finalidade proteger, em conformidade com a Lei $n^{\circ}$. 8.069, de 13 de julho de 1990, crianças e adolescentes expostos a grave ameaça no território nacional" (Decreto $n^{\circ}$. 6.231, 2007), podendo estender sua proteção a jovens de até 21 anos, que sejam egressos do sistema socioeducativo, e aos familiares do protegido, com o intuito de preservar a convivência familiar.

O modelo de atuação do PPCAAM é organizado pelo Guia de Procedimentos do Programa (Soares \& Egas, 2010, pp. 68-77), - qual estabelece uma equipe mínima para o seu funcionamento, composta por profissionais da área do Direito, do Serviço Social, da Psicologia e da Educação Social, que trabalham numa perspectiva interdisciplinar.

Nesse sentido, o Guia de Procedimento do PPCAAM afirma:

Considerando a complexidade envolvida na execução do Programa, marcada por múltiplas determinações, parte-se do pressuposto da valorização e da busca pela intervenção interdisciplinar. Entende-se tal prática como a de interação participativa que inclui a construção e pactuação de uma axiomática comum a um grupo de campos de saberes conexos com objetivos múltiplos, pautados pela horizontalidade nas relações de poder entre as áreas envolvidas (Soares \& Egas, 2010, p. 68). 
No PPCAAM, os procedimentos referentes à proteção iniciam-se com a solicitação de inclusão por uma das suas Portas de Entrada, que consistem no Conselho Tutelar, no Ministério Público ou no Poder Judiciário. Essas instituições, ao tomarem conhecimento de uma situação de ameaça de morte contra crianças, adolescentes ou jovens, comunicam formalmente a equipe do Programa, que agenda uma entrevista de avaliação no munícipio.

Confirmando a situação de ameaça, delibera-se pela inclusão do caso no Programa. Isso, com a devida anuência dos protegidos e a assinatura de um Termo de Compromisso, que contém as responsabilidades de cada pessoa ou instituição envolvida: protegidos, PPCAAM e instituição referente à Porta de Entrada.

Esse processo de proteção consiste na retirada imediata da criança, adolescente ou jovem ameaçado, bem como de seu núcleo familiar, do local onde se deu a ameaça, e no encaminhamento para um local seguro. Este é definido, sobretudo, a partir de avaliação técnica da equipe, que leva em conta, dentre outros fatores, a extensão da ameaça, o poder do ameaçador e a ocorrência de exposição midiática (Fernandes et al., 2015, p. 6).

Dentre as ações do Programa, são garantidas, aos protegidos, as condições para que se estabeleçam no novo local de moradia, buscando, para isso, articular a rede de serviços públicos em saúde, educação, assistência social, trabalho, cultura e lazer. O PPCAAM não trabalha com a ideia de refúgio protetivo, mas de inserção social segura com o núcleo familiar, sempre que possível (Soares \& Egas, 2010, pp. 6678). Em outras palavras, busca-se promo- ver a reinserção social em local seguro e desconhecido dos ameaçadores (Salatiel, 2014, p. 20).

Durante o período de proteção no PPCAAM, o trabalho de monitoramento por parte da equipe técnica mostra-se muito importante, na medida em que uma atitude, por mais simples que seja, pode revelar ao ameaçador a localização da família, colocando em risco não somente os incluídos, mas também os próprios profissionais do Programa. Por isso, torna-se necessário o cumprimento de normas de proteção, como seguir a orientação dos técnicos, não retornar ao local da ameaça, manter sigilo sobre a condição de protegido, não se expor nos meios de comunicação, etc. (Soares \& Egas, 2010, p. 72).

Sobre o público atendido pelo PPCAAM é possível traçar um perfil dos protegidos em todo o país, a partir da análise dos dados de casos incluídos no Programa no ano de 2014. ${ }^{6}$ Da implantação do PP. CAAM, em 2003, até dezembro de 2014, foram incluídas 8.090 (oito mil e noventa) pessoas, das quais 3.005 (três mil e cinco) representavam crianças, adolescentes ou jovens ameaçados de morte, e 5.085 (cinco mil e oitenta e cinco) representantes dos seus respectivos núcleos familiares. No ano de 2014, especificamente, o PPCAAM incluiu 246 (duzentas e quarenta e seis) pessoas, entre crianças, adolescentes e jovens, e 427 (quatrocentos e vinte e sete) familiares.

Na tabela abaixo, tais dados são discriminados de acordo com a equipe de origem dos protegidos:

${ }^{6}$ Os dados do PPCAAM apresentados neste tópico do artigo foram gentilmente disponibilizados pela Coordenação Geral de Proteção a Crianças e Adolescentes Ameaçados de Morte (CGPCAAM), na figura da Coordenadora Geral do período. 
Tabela 1 - Dados gerais dos incluídos (2014)

\begin{tabular}{|c|c|c|c|}
\hline ESTADO & CRIANÇA/ADOLESCENTE & FAMILIARES & TOTAL \\
\hline BA & 18 & 22 & 40 \\
\hline CE & 11 & 33 & 44 \\
\hline DF & 19 & 45 & 64 \\
\hline ES & 13 & 36 & 49 \\
\hline MG & 47 & 105 & 152 \\
\hline NTF & 7 & 15 & 22 \\
\hline PA & 17 & 18 & 35 \\
\hline PB & 15 & 29 & 44 \\
\hline PR & 18 & 28 & 46 \\
\hline PE & 14 & 26 & 40 \\
\hline RJ & 4 & 8 & 12 \\
\hline RS & 29 & 51 & 80 \\
\hline SP & 34 & 11 & 45 \\
\hline & 246 & 427 & 673 \\
\hline
\end{tabular}

Fonte: CGPAAM.

De maneira sintética, as principais características dos incluídos no PPCAAM, em 2014, podem ser quantificadas da seguinte forma: sexo masculino (73\%); raça negra (73\%); faixa etária entre 15-17anos (58\%); ensino fundamental incompleto $(85,4 \%)$; morador da capital (32\%); tem a genitora como principal referência familiar (64\%); renda familiar é de até 1 salário mínimo (63\%); e a ameaça se deve ao envolvimento com o tráfico de drogas (51\%).

Os dados gerais do PPCAAM confirmam as estatísticas de letalidade detalhadas no tópico anterior, na medida em que os protegidos são, em maior parte, adolescentes e jovens negros, do sexo masculino, que se encontram entre as principais vítimas da violência nos grandes centros urbanos.

Essa análise também pode ser confirma- da numa leitura mais detalhada dos dados referentes à idade, ao local e ao motivo da ameaça de morte dos incluídos no PPCAAM no ano de 2014. O gráfico 01 indica a distribuição etária dos protegidos no Brasil:

Gráfico 01 - Faixa etária dos protegidos

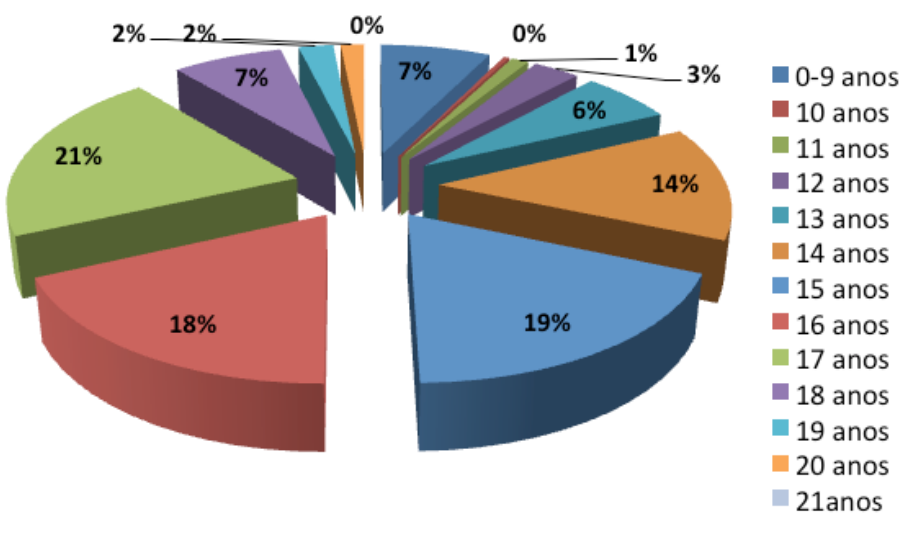

Fonte: CGPCAAM. 
Tal representação revela que a maioria dos protegidos do PPCAAM são adolescentes com 17 (dezessete) anos de idade (21\%). Se considerado o intervalo de 15 (quinze) a 17 (dezessete) anos, o valor representa 58\% do total de protegidos pelo PPCAAM no ano de 2014. Esse fato reforça a necessidade de uma política de proteção para a adolescência, uma vez que se verifica, nessa fase, uma quantidade expressiva de ameaças ao direito à vida.

O gráfico 02 , por sua vez, resume os dados relacionados ao local da ameaça:

Gráfico 02 - Local da ameaça

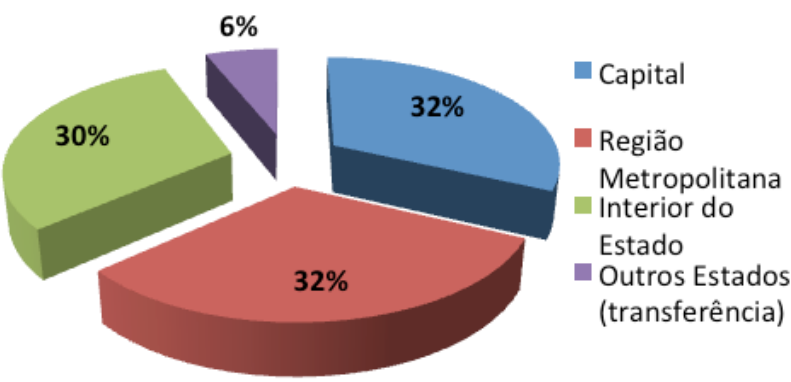

Fonte: CGPCAAM.

O cenário de ocorrência da maioria dos casos de ameaças de morte está dividido, igualitariamente, entre as capitais dos estados (32\%) e suas regiões metropolitanas (32\%). Nota-se, também, uma tendência de aumento das solicitações de inclusão no PPCAAM provenientes do interior dos estados.

Seja nas capitais, nas regiões metropolitanas ou no interior dos estados, dentre os atendidos pelo PPCAAM prevalecem aqueles que residem nos territórios de maior vulnerabilidade social dos municípios.

O próximo gráfico apresenta os motivos que caracterizam uma situação de ameaça de morte atendida pelo PPCAAM.
Gráfico 03 - Razão da ameaça

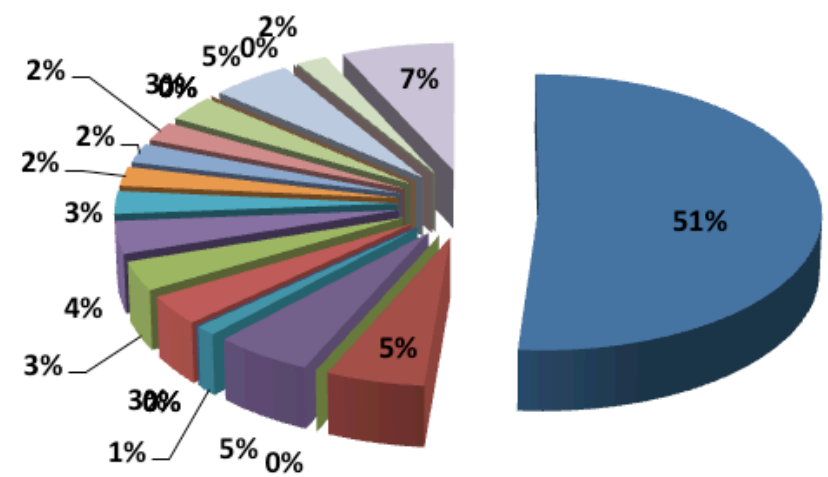

$$
\begin{aligned}
& \text { Interesse financeiro } \\
& \text { - Crime organizado } \\
& \text { Exploração sexual } \\
& \text { Abuso sexual } \\
& \text { Ameaça policial } \\
& \text { - Milícias } \\
& \text { Testemunha ocular } \\
& \text { Testemunha oficial } \\
& \text { - Vingança pessoal } \\
& \text { Religioso } \\
& \text { Racismo } \\
& \text { Homofobia } \\
& \text { Passional }
\end{aligned}
$$

Fonte: CGPCAAM.

Observa-se que os motivos das ameaças são diversos e compreendem diferentes violações de direitos, restando evidente, ainda, o papel do tráfico de drogas no cotidiano da maioria dos protegidos pelo PPCAAM.

A análise dos dados do PPCAAM aponta para uma realidade complexa, na qual a maioria dos protegidos pelo Programa pertence a grupos que sofrem histórica e cotidianamente outras formas de violência e de violação de direitos. Isto é, pertencem a grupos com elevado índice de vulnerabilidade, para o qual contribuem fatores como baixa 
renda, níveis baixos de escolaridade, vínculos familiares fragilizados e envolvimento com redes de criminalidade (Salatiel, 2014, pp. 20-21).

É nesse contexto que se torna fundamental a reflexão sobre o aperfeiçoamento da política de proteção, comprometida com a garantia dos direitos de crianças, adolescentes e jovens, inclusive, em face dos efeitos negativos da exposição pelos meios de comunicação.

\section{A RELAÇÃO ENTRE O PPCAAM E OS MEIOS DE COMUNICAÇÃO}

O Programa de Proteção a Crianças e Adolescentes Ameaçados de Morte compreende a proteção numa perspectiva integral, que se reflete, inclusive, em questões relacionadas à comunicação e à qualidade das informações veiculadas nos meios de comunicação sobre o público infantojuvenil. O Guia Metodológico do PPCAAM aborda a relação entre proteção e comunicação ao descrever a análise da gravidade da situação de ameaça e ao definir os compromissos para inclusão no Programa (Soares \& Egas, 2010, pp. 66-89). Percebe-se, entretanto, a necessidade de um estudo mais detalhado sobre tal assunto.

Indaga-se, por exemplo, como impedir, ou mesmo minimizar, os impactos e as violações de direitos decorrentes da exposição de crianças, adolescentes ou jovens protegidos pelos meios de comunicação?

Nesse sentido, no Encontro Nacional do PPCAAM, realizado em novembro de 2013, na cidade de Fortaleza, deliberou-se pela elaboração de um estudo capaz de analisar a complexa relação entre a proteção e os meios de comunicação, a partir das discussões das equipes estaduais do Programa.

A presente pesquisa, dentro das características e dos limites de um artigo científico, visa a contribuir com tal estudo, tendo como ponto de partida o levantamento e a sistematização de questões referentes aos casos em proteção com repercussão nos meios de comunicação, bem como as medidas adotadas pelas equipes do PPCAAM em contextos de exposição e violação de direitos dos protegidos.

Em vista disso, no início de 2014, em parceria com o Grupo de Trabalho Mídia e PP$\mathrm{CAAM}^{7}$, foi produzido um questionário específico a ser distribuído para as 12 (doze) equipes do PPCAAM em atividade no Brasil naquele período. Após dois meses, 10 (dez) equipes responderam o questionário - a saber, Ceará, Minas Gerais, Bahia, Núcleo Técnico Federal, Distrito Federal, Pernambuco, Espírito Santo, Rio Grande do Sul, Paraná, São Paulo - possibilitando o cruzamento de dados do intervalo de janeiro a dezembro de 2013.

Mesmo com realidades heterogêneas entre as equipes do PPCAAM, todos os representantes dos Programas que responderam o questionário apresentaram, pelo menos, uma referência de caso incluído em 2013 com repercussão nos meios de comunicação.

Isso pode ser visualizado no seguinte gráfico:

7 O Grupo de Trabalho Mídia e PPCAAM, criado em 2011, no Encontro Nacional do PPCAAM realizado no Rio Grande do Sul/RS, é formado por representantes das equipes estaduais e da Coordenação Geral do PPCAAM e tem como objetivo formular sobre a comunicação no contexto de proteção de crianças, adolescentes e jovens ameaçados de morte. 
Gráfico 04 - Equipes e casos em proteção expostos na mídia.

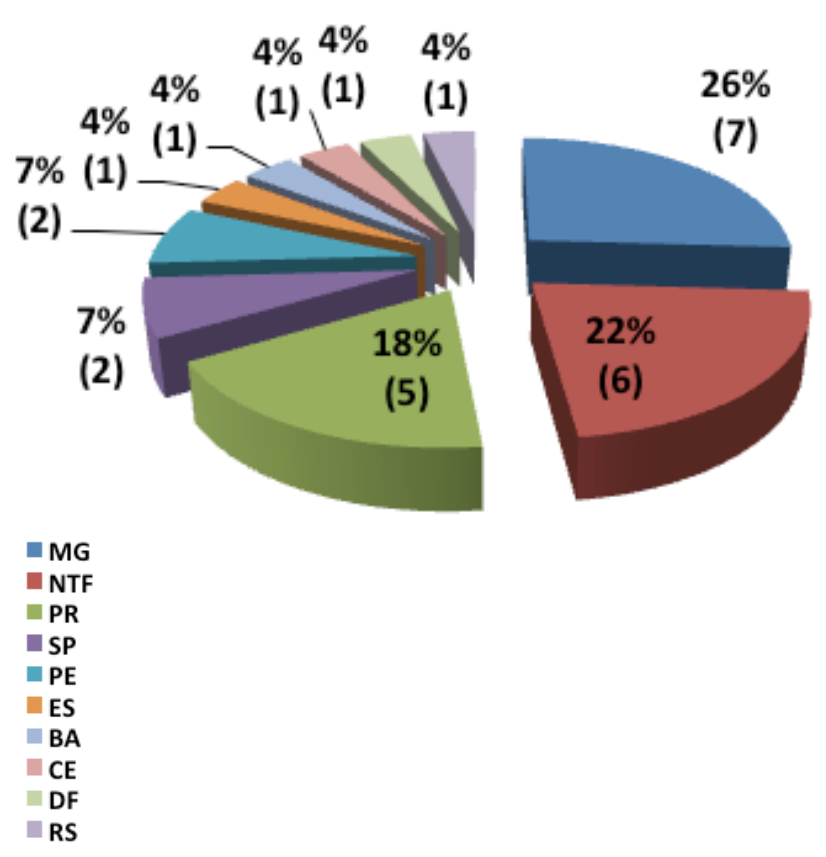

Fonte: Dados da pesquisa.

Conforme o Gráfico 04, foram identificadas 27 (vinte e sete) experiências com repercussão nos meios de comunicação no ano de 2013, com destaque para o número de casos acompanhados pelas equipes de Minas $\mathrm{Ge}$ rais (7), do Núcleo Técnico Federal (6) e do Paraná (5).

Os questionários revelaram uma grande diversidade na abrangência da repercussão nos meios de comunicação. Essa caracterização é importante, pois a dimensão da exposição midiática deve ser considerada na definição da estratégia de proteção do caso, bem como na análise dos impactos da exposição para o protegido ou sua família.

Dentre os 27 (vinte e sete) casos incluídos no PPCAAM em 2013, percebe-se um equilíbrio na dimensão de repercussão dos casos em nível local, regional, estadual e nacional, conforme demonstra o Gráfico 05:
Gráfico 05 - Abrangência da exposição e casos de proteção

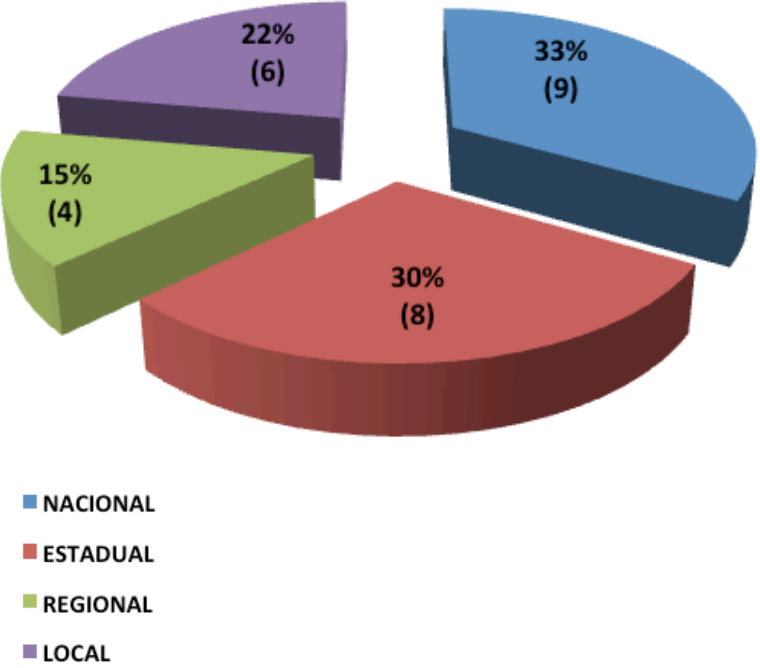

Fonte: Dados da pesquisa.

Outro ponto identificado nos questionários foi a variedade de formatos pelos quais os casos em proteção foram repercutidos nos meios de comunicação. Dos 27 (vinte e sete) casos citados, 20 (vinte) foram divulgados por jornais impressos e 15 (quinze) pela televisão. Além disso, foram apontados outros tipos de mídias, tais como rádio, jornal digital, revista impressa e redes sociais, conforme ilustrado no Gráfico 06:

Gráfico 06 - Tipos de meios de comunicação e casos em proteção

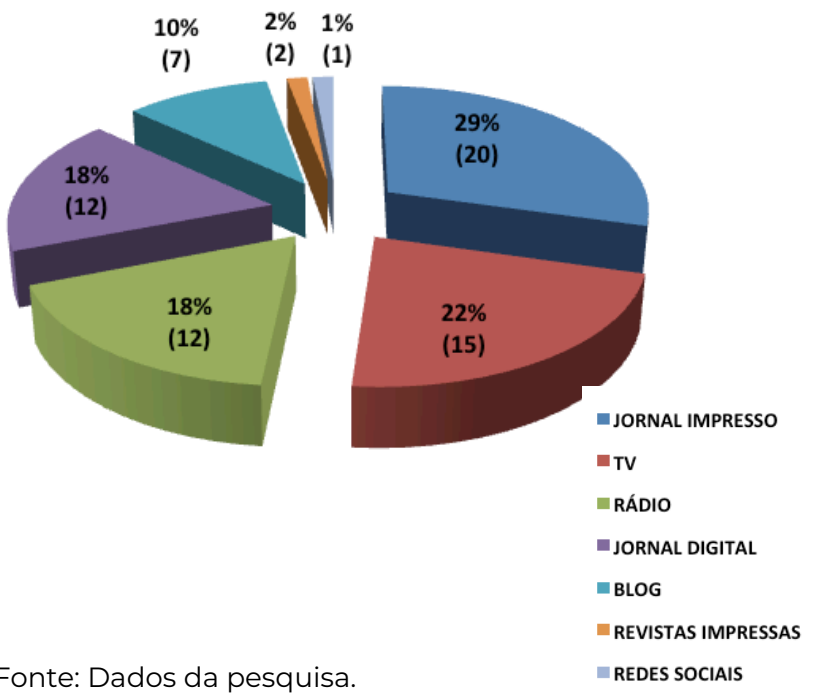


No mesmo sentido da definição da abrangência da repercussão midiática, a identificação do tipo de meio de comunicação utilizado também deve ser realizada no momento da escolha das medidas de proteção e da avaliação dos impactos gerados para o protegido. Exposições indevidas da imagem de um adolescente em proteção no jornal impresso ou no blog de domínio pessoal, por exemplo, apresentam reflexos diferentes, que devem ser analisados à luz do caso concreto.

O jornal impresso propicia grande evidência ao adolescente no momento da sua distribuição e possui maior influência para pautar outros canais de notícia. Já no blog de domínio pessoal, a imagem, geralmente, fica disponível por muito tempo e atinge grupos específicos com eficiência. Numa situação de abuso, o blog pessoal possui grande capacidade de replicação do conteúdo e o proprietário do site nem sempre é identificado, o que pode dificultar a sua responsabilização.

Na relação entre a mídia e direitos de crianças, adolescentes e jovens, especialmente daqueles incluídos no PPCAAM, é preocupante a maneira com que as reportagens identificam o público infantojuvenil. Apesar da tutela jurídica diferenciada dessas pessoas, não são raros os exemplos de atividade jornalística opondo-se aos limites impostos pela Constituição e pelo ECA no que se refere a tal tema.

Esse desrespeito fica ainda mais evidente quando se tratam de matérias sobre adolescentes em conflito com a lei, na medida em que as narrativas insistem no foco da violência contra a pessoa, em prejuízo da discussão sobre as políticas públicas relacionadas (ANDI, 2012, p. 4).
Segundo os dados dos questionários, das 27 (vinte e sete) experiências levantadas pelas equipes no ano de 2013, 15 (quinze) tiveram crianças, adolescentes ou jovens identificados, total ou parcialmente, pelos meios de comunicação, como traduzido no gráfico 07:

Gráfico 07 - Identificação e casos em proteção

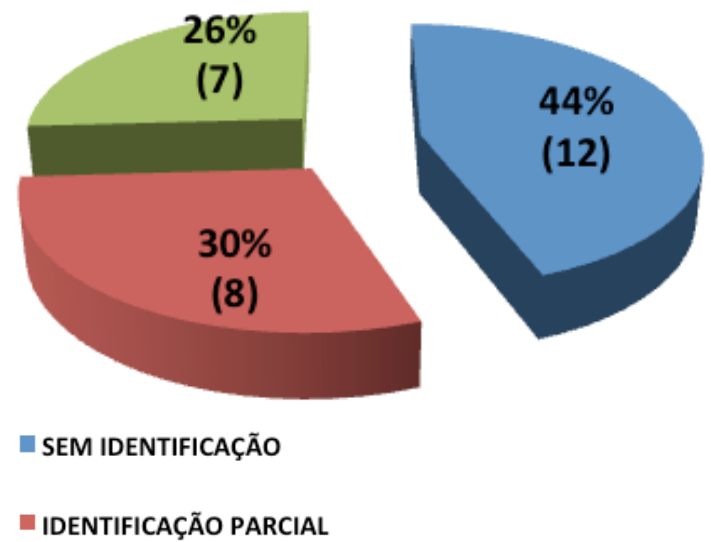

- IDENTIFICAÇÃO COMPLETA

Fonte: Dados da pesquisa.

Além das crianças, adolescentes e jovens em proteção, seus familiares também podem ser expostos na cobertura jornalística e, assim, fragilizar a segurança de todo o núcleo familiar protegido pelo Programa.

Os fatos retratados nos meios de comunicação, na maioria das vezes, relacionam os protegidos pelo PPCAAM ao contexto de violência das grandes cidades. $\mathrm{Na}$ análise feita pelas equipes estaduais do Programa sobre as fontes utilizadas pelos meios de comunicação, ficou evidente a difusão de um discurso de criminalização que privilegia a fala da autoridade policial sobre os fatos veiculados.

Do total de casos identificados na pesquisa, a maioria teve como fonte das notícias as autoridades policiais, seguidas, em representatividade, pelos familiares, pelos vizi- 
nhos e pelo Poder Judiciário, conforme representado no Gráfico 08:

Gráfico 08 - Fontes da atividade jornalística e casos em proteção

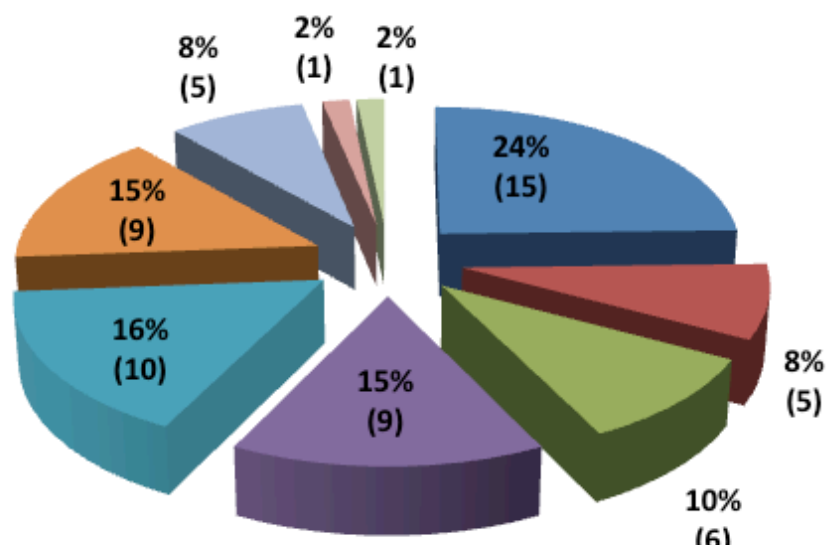

MINISTÉRIO PÚBLICO

I CONSELHO TUTELAR

- PODER JUDICIÁRIO

- FAMILIARES

VIZINHOS

ESPECIALISTAS

ASSESSORES PARLAMENTARES

REPRESENTANTES DA REDE

Fonte: Dados da pesquisa.

As equipes do PPCAAM também destacaram reflexos dessa exposição na reinserção social dos protegidos, como a necessidade de adoção de medidas de segurança mais rígidas, a reprodução de estereótipos e a revitimização do sujeito em proteção. São efeitos de difícil visualização, geralmente identificados no processo de adaptação da família no novo local de proteção.

Outro ponto de tensão percebido na síntese dos questionários foi o conjunto de situa- ções de abuso dos direitos dos protegidos na abordagem efetuada pelos meios de comunicação. Das 10 (dez) equipes do PPCAAM que responderam o questionário, 07 (sete) afirmaram que identificaram situações concretas de abuso por parte dos meios de comunicação. Sobre as situações de abusos, as equipes destacaram questões como: a identificação dos protegidos, geralmente, associada à prática de atos infracionais; a exposição dos adolescentes no momento da sua apreensão ou durante as audiências judiciais; o estímulo da exposição dos protegidos por parte dos agentes de segurança pública e do sistema de justiça; a reprodução de notícias preconceituosas e que desconsideram a versão dos fatos apresentada pelos protegidos e seus familiares.

Ademais, mesmo com a avaliação de todas as equipes quanto à importância de serem tomadas medidas que impeçam ou atenuem a situação de violação de direitos, a maioria das respostas alertou sobre a dificuldade de serem efetuadas tais ações. Para exemplificar, cita-se que, das 07 (sete) equipes que identificaram uma situação de abuso, somente 04 (quatro) informaram a adoção de alguma medida sobre o assunto.

Quanto às medidas adotadas pelas equipes do PPCAAM diante das situações de abuso, os questionários mencionaram a solicitação de retirada de dados dos protegidos; a denúncia e o pedido de intervenção do Ministério Público e do Poder Judiciário; o contato com os meios de comunicação que divulgaram a notícia; e a articulação com a Coordenação Geral do Programa e com outras entidades parceiras da sociedade civil, como o Centro de Defesa da Criança e do Adolescente (CEDECA).

Essas informações estão sintetizadas no Gráfico 09: 
Gráfico 09 - Equipes do PPCAAM, casos de abuso e medidas adotadas

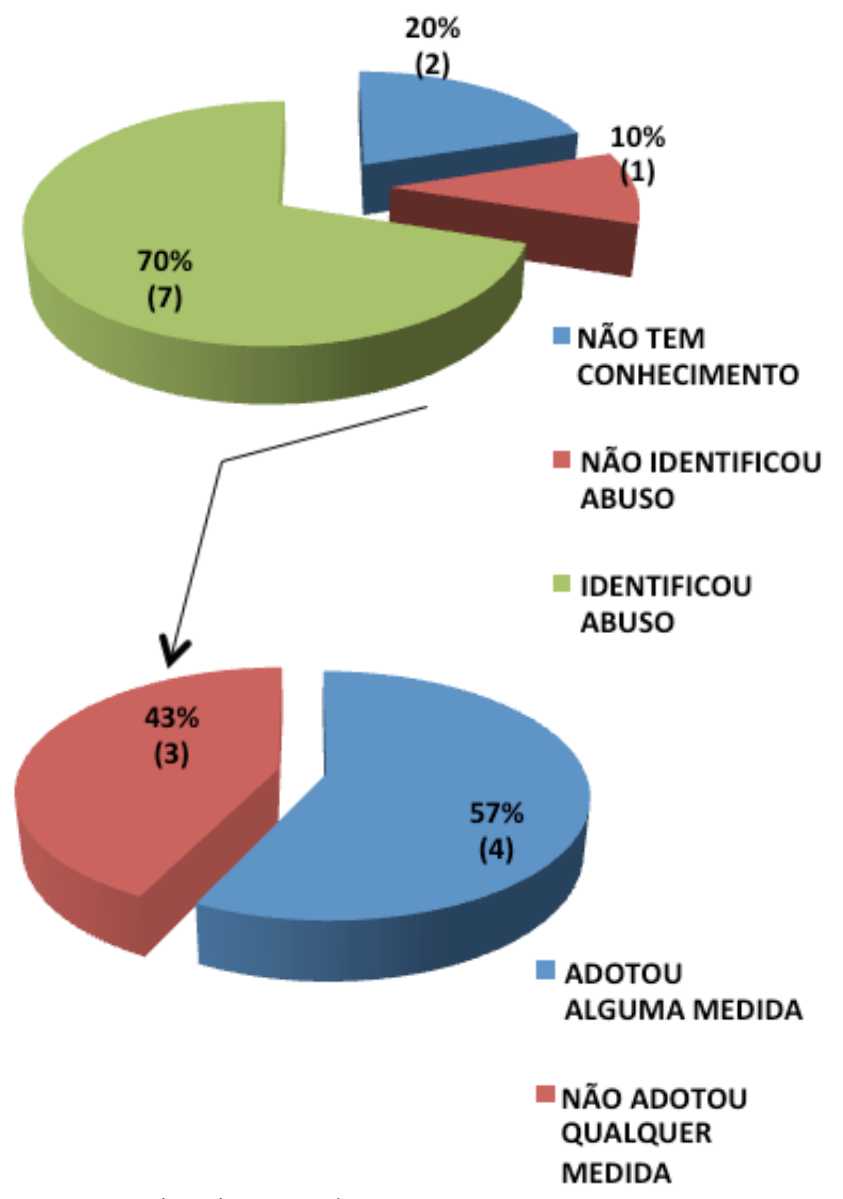

Fonte: Dados da pesquisa.

Nota-se, por último, que as situações de abuso por parte dos meios de comunicação podem, em última instância, prejudicar, ou mesmo inviabilizar, a finalidade desta política em garantir o direito fundamental à vida dos seus protegidos.

Dessa forma, a compreensão do limite do direito à liberdade de informação jornalística quanto a fatos relacionados a pessoas em situação de risco extremo, a exemplo do público atendido pelo PPCAAM, passa, essencialmente, pela compatibilização dessa liberdade com a necessidade da preservação da identidade, da individualidade e da privacidade de crianças, adolescentes e jovens ameaçados de morte.

\section{CONCLUSÕES}

Nas últimas décadas, os meios de comunicação provocaram grandes transformações nas relações sociais e jurídicas do país, levantando desafios inéditos com relação à proteção dos direitos fundamentais da pessoa humana, notadamente, aqueles que envolvem crianças, adolescentes e jovens expostos indevidamente pelos veículos de comunicação.

Nesse contexto, a integração das tecnologias de comunicação e informação torna-se emblemática, uma vez que simboliza um conjunto de mudanças na organização da sociedade em rede e traz à tona novas contradições a serem compatibilizadas pela ordem jurídica constitucional e infraconstitucional.

Quando se analisa a relação entre os meios de comunicação e a representação do público infantojuvenil, especialmente, aquele que se aproxima do perfil atendido pelo PPCAAM, percebe-se que o uso da imagem desse público como uma forma de espetáculo e de banalização da violência, sem qualquer compromisso ético ou social, ganha força em uma sociedade midiatizada, potencializada por plataformas multimeios. Em TVs, rádios, computadores e celulares o desejo por punição e contenção dos indesejáveis permanece atual, como uma reposta ao medo e à sensação de insegurança da sociedade.

Considerando os profissionais e os protegidos inseridos na política do Programa de Proteção a Crianças e Adolescentes Ameaçados de Morte, conclui-se que uma ordem jurídica robusta na defesa dos direitos fundamentais relaciona-se diretamente com a finalidade da política pública de proteção a pessoas em situação de extremo ris- 
co. A adequada regulamentação da proteção do direito à privacidade, à intimidade, à imagem, ao nome, dentre outros, aumenta sensivelmente a capacidade de atuação do PPCAAM na construção de ações de segurança que garantam, em última instância, a preservação do direito à vida dos usuários dessa política.

Vale ressaltar que este artigo compartilha da esperança do convívio entre a atividade comunicacional e o dever de proteção dos direitos humanos de crianças, adolescentes e jovens. Em uma sociedade democrática, a liberdade dos meios de comunicação deve ser ampla, mas nunca absoluta, ao ponto de anular problematizações sobre o seu fazer e silenciar o debate público e crítico sobre o tema.

Quando os meios de comunicação estão diante do conflito da sua liberdade com outros direitos igualmente protegidos pelo texto constitucional, esses meios também possuem a responsabilidade de exercer sua atividade de forma qualificada, respeitando os direitos humanos do público infantojuvenil e os limites da ordem democrática que afastam a sociedade de um estado barbárie e de banalização da violência.

\section{REFERÊNCIAS}

Agência de Notícias dos Direitos da Infância. (2012). Imprensa e racismo: uma análise das tendências da cobertura jornalística. Recuperado em 26 de abril, 2019, de http://www.andi.org.br/inclusao-e-sustentabilidade/publicacao/imprensa-e-racismo.

Anistia Internacional. (2015). Diga não à execução. Recuperado em 26 de abril, 2019, de https://anistia.org.br/ campanhas/diga-nao-execucao/.

Batista, V. M. (2012). Adesão Subjetiva à Barbárie. In V M. Batista (Org.). Loïc Wacquant e a questão penal no capitalismo neoliberal (pp. 1-4). Rio de Janeiro: Revan. Bauman, Z. (2008). Medo líquido. Rio de Janeiro: Zahar. Cano, I. Borges, D. (org.) (2017). Homicídios na Ado- lescência no Brasil. IHA 2014. Recuperado em 10 de novembro, 2018 de http://www.crianca.mppr.mp.br/ arquivos/File/publi/obs_favelas/iha_2014.pdf.

Debord, G. (2000). A Sociedade do Espetáculo. Rio de Janeiro: Contraponto.

Decreto n. 6.231, de 11 de outubro de 2007. (2007). Institui o Programa de Proteção a Crianças e Adolescentes Ameaçados de Morte - PPCAAM. Brasília. Recuperado em 20 de abril, 2017, de http://www.planalto.gov.br/ccivil_03/_Ato2007-2010/2007/Decreto/D6231.html

Fernandes, R. M. Salatiel, E. L. Azevedo, A. C. O. (2016). A segurança de dados na internet e o programa de proteção: um estudo sobre as experiências do PPCAAM/ MG. In Polido, F. B. P. Anjos, L. C. (Org.). Marco civil e governança da internet: diálogos entre o doméstico e o global (pp. 53-70). Belo Horizonte: Iris.

Ferraz, J. D. F. Castro Júnior, J. L. P. Vieira, F. O. Cordeiro, W. (2011). O funcionamento do Programa de Proteção a Crianças e Adolescentes Ameaçados de Morte (PPCAAM) nas áreas de vulnerabilidade social no Rio de Janeiro. Revista Política Públicas, 15(2), 277-286.

Igreja, R. L. (2017). O Direito como objeto de estudo empírico: o uso de métodos qualitativos no âmbito da pesquisa empírica em Direito. In M. R. Machado (Org.). Pesquisar empiricamente o direito (pp. 11-38). São Paulo: Rede de Estudos Empíricos em Direito.

Instituto de Pesquisa Econômica Aplicada \& Fórum Brasileiro de Segurança Pública. (2018). Atlas da Violência em 2018. Recuperado em 10 de outubro, 2019, de http://www.ipea.gov.br/portal/index.php?option=com_content\&view=article\&id=33410\& 1 temid=432.

Martini, S. (2008). Os Meios, Atores ou Gerenciadores da Comunicação Política? Reflexões Desde a Notícia Policial na Imprensa Gráfica Argentina. In A. Fausto Neto, P. G. Gomes, J. L. Braga, J. L., Ferreira, J. (Org.). Midiatização e Processos Sociais na América Latina (pp. 10-30). São Paulo: Paulus.

Michaelis (2018). Dicionário Brasileiro da Língua Portuguesa. Recuperado em 14 de maio, 2019, de http:// michaelis.uol.com.br/busca?id=Pqyzk.

Minayo, M. C. S. Assis, S. G. Souza, E. R. Njaine, K., Deslandes, S. F. Silva, C. M. F. P. Fraga, P. C. P. Gomes, R. Abramovay, M. Waiselfisz, J. J. Monteiro, M. C. N. (1999). Fala galera: juventude, violência e cidadania na cidade do Rio de Janeiro. Rio de Janeiro: Garamond.

Oliveira, C. S. Soares, M. U. Nicodemos, C. (2011). Caminhos para uma política de Estado de enfrentamento ao assassinato de crianças e adolescentes no Brasil: proteção à vida e ao interesse superior da criança e do 
adolescente. Rio de Janeiro: Org. de Direitos Humanos Projeto Legal.

Patias, J. C. (2012) O espetáculo no telejornal sensacionalista. In Coelho, C. N. P. Castro, V. J. Castro (Org.). Comunicação e sociedade do espetáculo (pp. 81-106). São Paulo: Paulus.

Richard, I. (2015). Negros são 2,5 vezes mais vítimas de armas de fogo do que brancos no Brasil. Brasília: EBC. Recuperado em 14 de maio, 2019, de http://www.ebc. com.br/noticias/2015/05/negros-sao-25-vezes-mais-vitimas-de-armas-de-fogo-do-que-brancos-no-brasil.

Salatiel, E. L. (2014) Fracasso Escolar e Criminalidade: uma abordagem de trajetórias escolares de adolescentes ameaçados de morte em proteção no estado de Minas Gerais (Trabalho de Conclusão de Curso). Instituto DH/Instituto Santo Tomás de Aquino, Belo Horizonte, Minas Gerais, Brasil.

Soares, M. U. Egas, H. A. P. B. (2010) Programa de proteção a crianças e adolescentes ameaçados de morte: PPCAAM. Brasília, Presidência da República. Recuperado em 20 de abril, 2019, de http://www.crianca.mppr. mp.br/arquivos/File/publi/sedh/ppcaam_livro_2010. pdf.

Trevisan, M. C. (2014). O racismo que mata. Rio de Janeiro: Radis na Rede. Recuperado em 20 de abril, 2019, de http://www6.ensp.fiocruz.br/radis/radis-na-rede/o-racismo-que-mata.

United Nations Children's Fund. (2015). ECA 25 anos. Estatuto da Criança e do Adolescente: avanços e desafios para a infância e a adolescência no Brasil. Recuperado em 20 de abril, 2017, de http://www.unicef.org/ brazil/pt/ECA25anosUNICEF.pdf.

Waiselfisz, J. J. (2015). Mapa da Violência 2015: mortes matadas por arma de fogo. Brasília: Portal da Juventude. Recuperado em 20 de abril, 2017, de www.juventude.gov.br/juventudeviva.

Data de submissão: 31/05/2017

Data de aceite: 09/03/2020 